\title{
Smart Shopping Cart using RFID Technology
}

\author{
Alat Laxmi ${ }^{1}$, Bhalerao Shraddha ${ }^{2}$, Chothave Ajay ${ }^{3}$, Pathan Samreen ${ }^{4}$ \\ B.E Student, Information Technology, VPKBIET, Baramati, India ${ }^{1,2,3,4}$
}

\begin{abstract}
A shopping mall is a place where wide varieties of items are available. Many shopping malls use barcode scanning system. As this system is time consuming, people have to wait in a long queue at the billing counter. To overcome this problem, smart shopping cart is introduced. This proposed system uses RFID technology. Every product is attached with Radio Frequency Identification (RFID) tag. For scanning this tag RFID reader is used which is attached to the cart. As a result bill is generated in the cart itself and is displayed on the LCD which saves the time of the customer.
\end{abstract}

Keywords: Radio Frequency Identification, Liquid Crystal Display

\section{INTRODUCTION}

IoT is a network in which all physical objects are connected to the internet through network devices or routers and exchange data. IoT is very intelligent technique which reduces human efforts as well as gives easy access to physical devices. "Things" in IoT sense, is the mixture of hardware, software, data and services. It also refers to a variety of devices. These devices gather useful data with the help of varying existing technologies and share that data among other devices. IoT has many applications in different fields such as healthcare, smart homes, wearable devices, etc. In this paper we discuss on smart shopping cart system which is based on RFID technology. Now a day, shopping at big malls is becoming daily activity in metro cities. The best ways to help the customers is to reduce the time spent in shopping, reduce cost of items and automated billing.

In shopping malls various technologies are used like Barcode system, Mobile technology (using Android App), etc. In these system customers have to wait in long queue for billing. Hence, we proposed the new idea using IOT (Internet of Things).In this system RFID (Radio Frequency Identification) Technology is used. Every item or product is attached with a RFID tag and this product is scanned using RFID reader which is attached with a trolley. Customer purchase different items and put them in the trolley. Price of that total items and also names will be displayed on LCD (Liquid Crystal Display) screen which is also attached with a trolley. If a customer wants to remove some items, they have to rescan the item which will delete it from the total bill. In this system, customer's time is reduced at the time of shopping in the malls.

\section{RELATED WORK}

IoT is a popular topic in recent years. There are many applications of IoT; Smart Shopping Cart is one of its applications. There are some research works being published in recent years regarding improving customers' shopping experience. There were multiple attempts made in 2003. Shanmugapriyan [2] proposed a basic design using RFID and barcode reader for product identification using Zig-Bee for communication between server and the cart.

MR.P.Chandrasekar in "Smart Shopping Cart with Automatic billing System through RFID and Zig-Bee" [8] proposed to develop a shopping cart with a Product Identification Device (PID) which will contain microcontroller, a LCD, EEPROM, a reader and zig-bee. In implementation with RFID and Zig-Bee. In 2011, Klajan and Pie [3] proposed an idea of tracking a customer and knowing customer's interests. The idea of smart carts and smart shelves were also discussed in their work.

Raju Kumar et. Al. [4] in "Intelligent Shopping Cart" explains how to access real time information about the diverse product inside the shopping cart. Ali and Sonkusare [10] designed a smart cart system with navigation. It included the implementation of smart shelves, which tells when the smart carts enter an aisle and delivered product information to carts. There are many more designs in this area. In all previous designs, customer had to scan the items one-by-one manually, which is not convenient. Difference between RFID and barcode technology is, RFID does not require lie-ofsight reading but barcode depends on it. RFID can achieve distance reading, which intellectually brings the property of IoT. 


\section{PROSED SYSTEM}

In proposed system every product has a unique RFID tag attached to it.Attached tag contains not only cost of the product but also additional information related with product like product name, manufacturing date, expiry date, etc. While customer put the product in the cart at that time the RFID reader reads that RFID tag attached to that product.

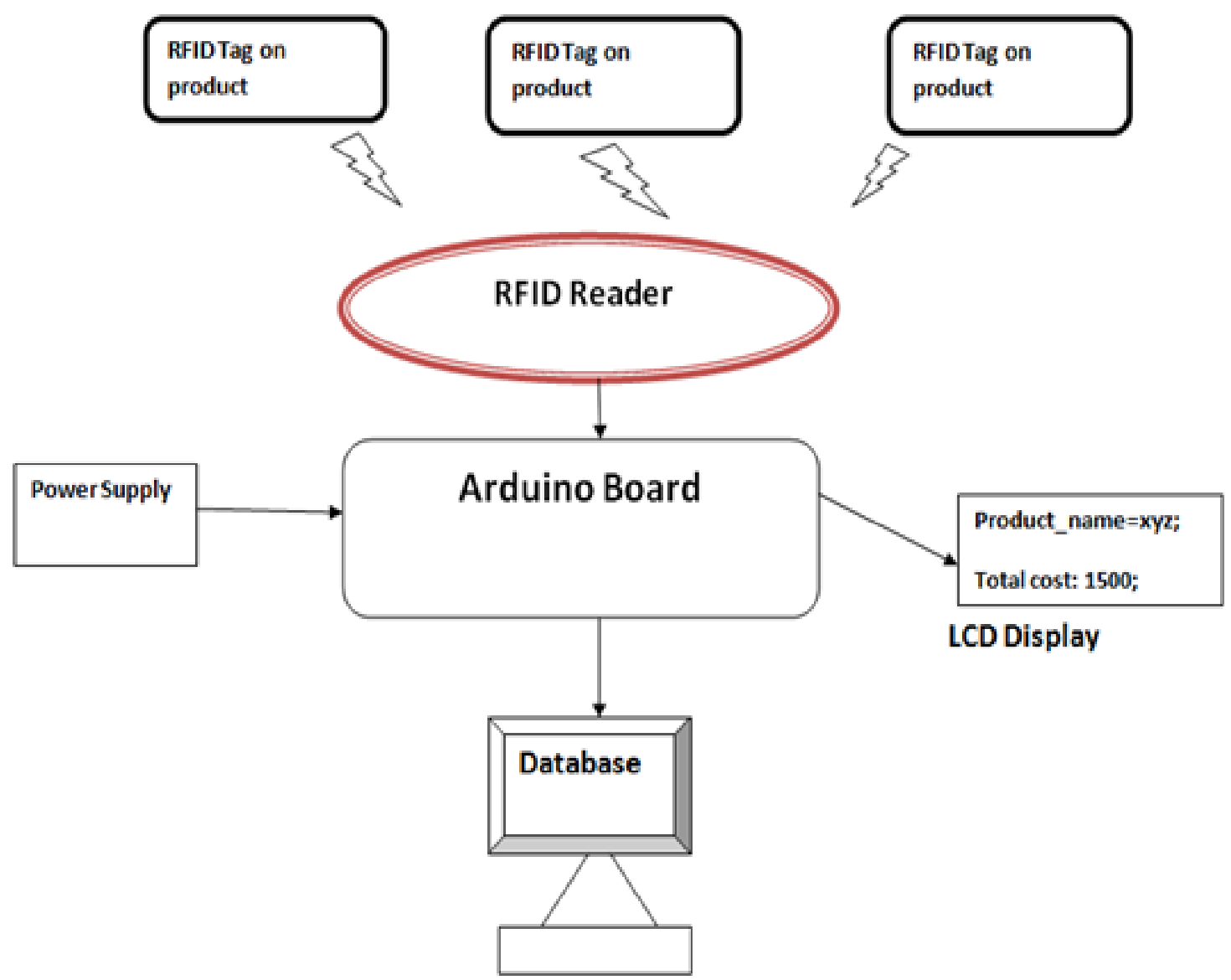

Fig: 1. Block diagram of Proposed System

The RFID reader will sends this information to the Arduino Board for further process. Arduino performs various operations on the information received by RFID reader by reading RFID tag attached to the product .With the help of Arduino, LCD Display will show the name and total cost of the product. If customer wants to remove any product from list of the purchased product which is already in cart, then customer can remove that product by rescanning that product's Tag. 


\section{WORKFLOW OF THE SYSTEM}

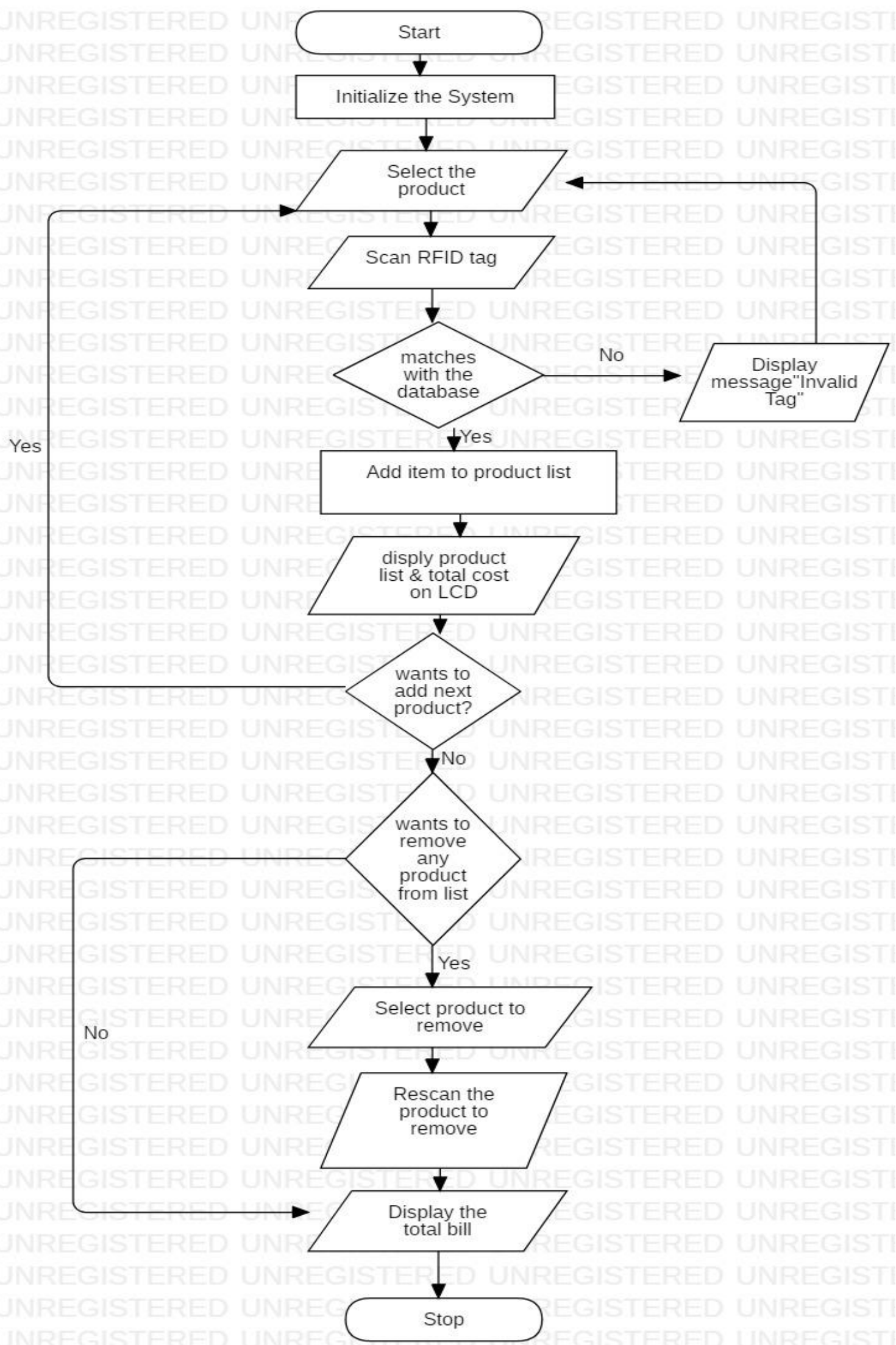


Vol. 7, Issue 11, November 2018

\section{HARDWARE USED IN THE SYSTEM}

A. RFID Tag: Every product in the mall is attached with a RFID tag. The tag not only provides the cost of the product but also provide additional information such as product name, manufacturing date, expiry date, type of the product, etc. RFID system consists of RFID tag made up of microchip with an antenna, and a reader with an antenna. Data stored within a RFID tag's microchip waits to be read. The tag's antenna receives electromagnetic energy from RFID reader.
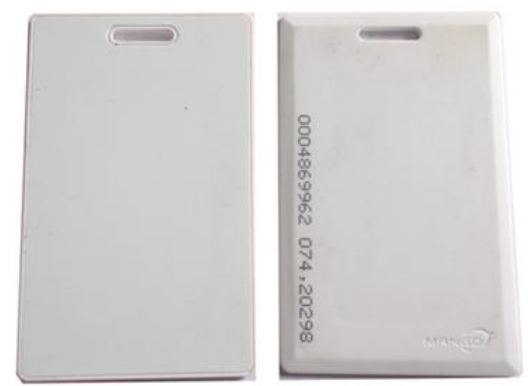

B. RFID Reader: RFID reader will not only read the tags but also perform many more operations on data received from tag. So it is called as "smart RFID reader". This is possible because RFID reader will be connected with arduino board. RFID reader sends the data after reading every tag to the arduino. It does not require line-of-sight .So it can read multiple tags at a time. This is the main advantage of RFID reader.

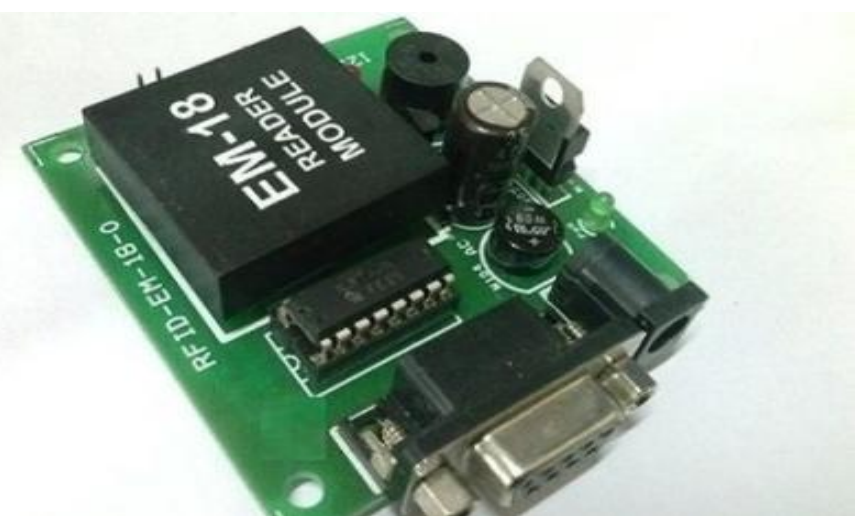

C. Power supply: The AC supply is applied to the step down transformer

D. Arduino: Arduino is a microcontroller board. The arduino has its own software to burn programs into it. It uses its own programming language. We will be connecting the RFID reader output to the serial communication port of the arduino board. Also LCD display will be connected with the arduino board. RFID reader sends the data to the arduino controller. The controller works on these data, it sends the result to the LCD display. The arduino adds the total cost of all the items in the cart and transmits this information to the LCD display.

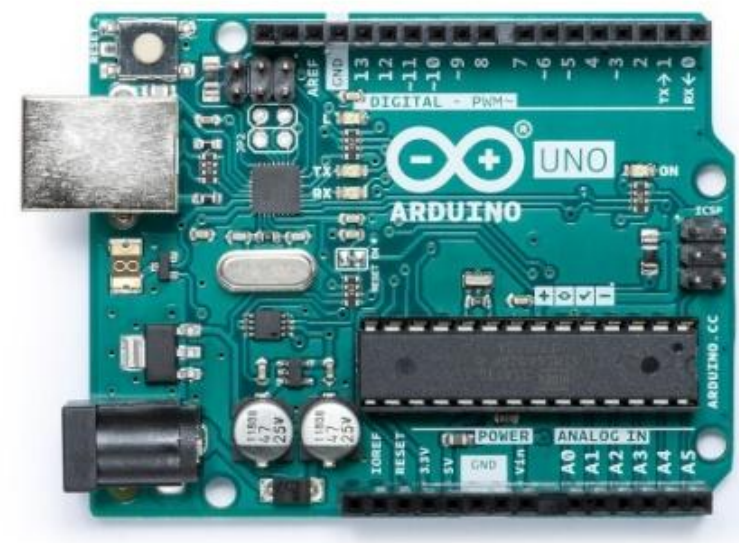


E. LCD Display: Here the LCD display is used to display the bill. The display is connected to I/O port of arduino.

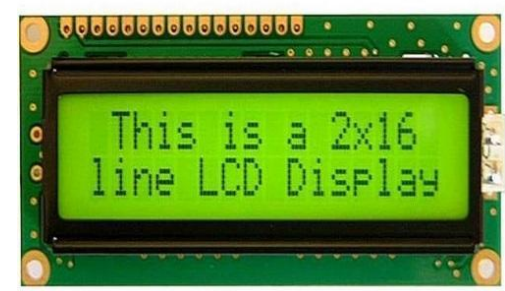

F. Transformer: We will use the Step down transformer to convert the AC from power supply to the $4 \mathrm{~V}$.

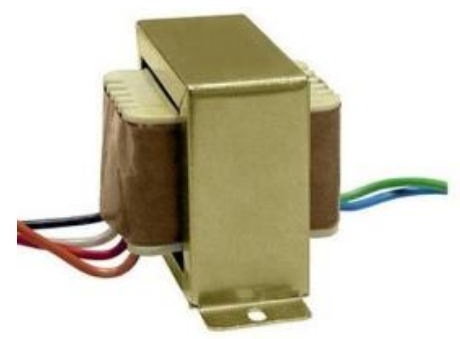

\section{CONCLUSION}

In this paper, we focused on requirements for smart shopping system using RFID technology. We have given a brief introduction about how system will work. This system is much beneficial as compared to barcode system. We believe that adapting this system in future for stores will be easy and efficient. It also provides customers better services and improves customer experiences.

\section{REFERENCES}

[1]. Ruinian Li, Tianyi Song, Nicholas Capurso, Jiguo Yu, Jason Couture, and Xiuzhen Cheng, Fellow, IEEE, "IoT Applications on Secure Smart Shopping System". IEEE Internet of Things Journal, vol. 4, No. 6, December 2017.

[2]. T. Shanmugapriyan, "Smart cart to recognize objects based on user intention," Int. J. Adv. Res. Compt. Com. Eng., vol. 2, no. 5, 2013 , pp. $2049-2053$.

[3]. D. Klabjan and J. Pei, "In-store one-to-one marketing," J. Retailing Consum. Services, vol. 18, no. 1, pp. 64-73, 2011.

[4]. Raju Kumar, K. Gopalakrishna2, K. Ramesha3,” Intelligent Shopping Cart”, IJESIT, vol. 2, Issue 4, July 2013.

[5]. Ankit Anil Aggarwal, "RFID Based Automatic Shopping Cart", The International Institute for Science, Technology and Education journal on Control Theory and Informatics ,vol.1, no.1, 2011.

[6]. B. N. Arathi and M. Shona, "An Elegant Shopping using Smart Trolley" India Journal of Science and Technology, Vol. 10 , Issue 3, Jan 2017.

[7]. Galande Jayshree, Rutuja Gholap, Preeti Yadav, "RFID Based Automatic Billing Trolley", International Journal of Emerging Technology and Advanced Engineering, Vol. 2, Issue 12, Dec 2013.

[8]. P. Chandrasekar and T. Sangeetha, "Smart shopping cart with automatic billing system through RFID and ZigBee," in Proc. IEEE Int. Conf. Inf.Commun. Embedded Syst. (ICICES), Chennai, India, 2014, pp. 1-4.

[9]. Bala Krishnan, Shiyam Sundaran, Dharun Prasath, Guna Kishore, "RFID Based Smart Shopping Kart”, IRJET , Vol. 5 ,Issue 1, Jan 2018.

[10]. Z. Ali and R. Sonkusare, "RFID based smart shopping and billing," Int.J. Adv. Res. Comput. Commun. Eng., vol. 2, no. 12, pp. 4696-4699, 2013.

[11]. Bansi.G.Jain and Divyank Shah, "IoT based retailed shopping system using NFC", IJARIIT, vol. 4, Issue 3.

[12]. Sagar Sojitra and Rahul G. Patel, "A Review of Smart Shopping Systems”, IRJET, Vol. 3, Issue 5, May 2016. 